\title{
Agreement between postmortem endometrial cytology, biopsy and bacteriology in culled dairy cows
}

\author{
Beatríz Maríno Fuentes ${ }^{1}$, Luis Angel Quintela Arias ${ }^{1,3}$, Juan José Becerra González ${ }^{1}$, Lidia del Barrio del \\ Sol $^{1}$, Jesús Enrique Mociños Feijóo ${ }^{1}$, José Luis Guillín Puñal ${ }^{1}$, Mónica Barrio López ${ }^{1}$, Alberto Prieto Lago \\ José Manuel Díaz Cao², Gonzalo Fernández Rodríguez², Pedro José García Herradón', \\ Ana Isabel Peña Martinez \\ ${ }^{1}$ Unit of Reproduction \& Obstetrics, Department of Animal Pathology; Faculty of Veterinary Medicine, University of Santiago \\ de Compostela, Lugo, Spain. \\ ${ }^{2}$ Unit of Infectious Diseases, Department of Animal Pathology; Faculty of Veterinary Medicine, University of Santiago de \\ Compostela, Lugo, Spain.
}

\begin{abstract}
The objectives of this study were to determine: a) the agreement between postmortem endometrial cytology, uterine biopsy and presence of intrauterine fluid in apparently normal genital tracts collected from culled dairy cows; b) the agreement between results obtained from paired uterine horns using the different diagnosis methods; and c) the microorganisms isolated from uteri with cytological endometritis. One hundred grossly normal genital tracts from Holstein cows were collected at a local slaughterhouse. Samples for cytology, histopathology and bacteriology were obtained from both uterine horns, and presence of any intrauterine content was determined after opening the tracts. Cut-off values used for positive cytology were $\geq 5 \%$ PMN (polymorphonuclear neutrophils). Data were analyzed by ROC curve analysis, Cohen's Kappa method and Chi-square tests. Presence of inflammatory infiltrate and its endometrial distribution were the only histological parameters significantly correlated with cytology results (AUC: 0.780 and 0.694 , respectively). Agreement between histology and cytology was moderately high for presence of infiltrate $(\mathrm{kappa}=0.55)$ and low for infiltrate distribution $(\mathrm{kappa}=0.33)$. Other histological parameters (status of endometrial epithelium, endometrial glands or fibrosis), intrauterine content or bacteriology were not correlated with cytology. Presence of intrauterine content was significantly $(\mathrm{P}=0.036)$ related with biopsy results. Moderately high agreement was observed between paired uterine horns for cytology (kappa $=0.65)$ and biopsy $(\mathrm{kappa}=0.74)$. Bacteriology was not related with cytology or biopsy, but different bacteria were isolated from cytology negative or positive uteri. It was concluded that endometrial cytology, although less sensitive than biopsy, is a useful tool for diagnosing subclinical endometrial inflammation.
\end{abstract}

Keywords: dairy cattle, endometrial cytology, endometrial histology, microbiology, subclinical endometritis.

\section{Introduction}

Reproductive efficiency of dairy cattle is of utmost importance for milk production as it significantly affects its profitability. The main objective of reproductive management in dairy farms is to get the cows pregnant in an optimal interval after calving (Plazier et al., 1997; Walsh et al., 2011). During the last decades a progressive and worrying decrease in fertility of dairy cows has been detected in many countries, being estimated to decline around $0.5-1 \%$ per year (Royal et al., 2000; Lopez-Gatius, 2003). Fertility decrease in dairy cows may be caused by numerous factors, such as genetic background, inadequate feeding, bad reproductive management, poor welfare conditions or reproductive diseases, and not entirely associated to an increase in milk production (Lucy, 2001).

Among reproductive diseases, postpartum uterine pathologies are the main causes of poor reproductive performance and economic losses (Sheldon et al., 2006) due to infertility, higher culling rates, reduced milk production and increased costs for treatments (Bartlett et al., 1986; Guard, 1994). Several studies have shown that subclinical endometritis (SCE) is a common disease in the postpartum of dairy cows and that is highly associated with poor reproductive performance (Kasimanickam et al., 2004; Gilbert et al., 2005; Barrio et al., 2015).

Subclinical endometritis is defined as inflammation of the endometrium in the absence of clinical signs of endometritis (Sheldon et al., 2006) and characterized by an infiltrate of polymorphonuclear neutrophils (PMN) without or with minimal intrauterine exudate (Földi et al., 2006). Uterine cytology is the most used tool for SCE diagnosis (Kasimanickam et al., 2005) and cytobrushing is considered the best technique for endometrial sample collection as it is easy and quick to perform (Barlund et al., 2008), and it is also safe and effective (Oral et al., 2009). Evaluation of endometrial cytology has been done based on the number of PMN counted per 100 nucleated cells (Melcher et al., 2014) or the mean number of PMN observed in 10 microscopic fields (Prieto et al., 2012). Discrepancies exist in relation to the cut off values of PMN that should be considered as diagnostic of SCE depending on the days in milk (DIM; Melcher et al., 2014).

Other methods used for the diagnosis of clinical endometritis in cows and that could be also valid for diagnosing SCE are: a) ultrasonography, by evaluating the presence of fluid in the uterine lumen, 
horn and cervical diameters (Kasamanickan et al., 2004; Meira et al., 2012) and ecotexture of the uterine walls (Küçükaslan et al., 2014); b) uterine biopsy, by histologic evaluation of the endometrium (Meira et al., 2012; Madoz et al., 2014); and c) bacteriology, by the isolation and identification of microorganisms present in the uterus (Lazzari et al., 2011; Madoz et al., 2014).

Although endometrial cytology, from a practical point of view, is considered the best tool for diagnosing SCE, its efficiency to detect inflammatory lesions remains to be established. Agreement with other diagnostic methods has been evaluated only in a few studies and it has been found to be low (Kasamanickan et al., 2004; Meira et al., 2012; Madoz et al., 2014). On the other hand, uterine samples for cytology or biopsy in live animals are usually collected from one horn, but whether they are representative of both uterine horns has not been investigated. Also the relationship between presence of endometrial inflammation and bacterial or viral infection has not been extensively evaluated.

Therefore, the objectives of this study were to determine: a) the agreement between endometrial cytology, uterine biopsy and presence and type of uterine content in macroscopically normal uteri; b) the agreement between the results obtained from the two horns of a uterus using the different diagnosis methods; and c) the presence and type of microorganisms isolated from uteri with or without cytological endometritis.

\section{Materials and Methods}

\section{Postmortem collection of reproductive tracts}

Between February and May 2014, 395 genital tracts from dairy cows were collected at a local slaughterhouse (Novafrigsa, Lugo, Spain). Before excision from abdominal and pelvic viscera, the cranial end of each uterine horn and the cervix were closed with nylon ties to avoid subsequent contamination of uterine lumen.

Excised genital tracts were examined by visual inspection and palpation. Reproductive tracts with gravid uterus, gross lesions in ovaries, oviducts, uterus or vagina, with palpable intrauterine fluid or vaginal discharge, and reproductive tracts with signs of incomplete postpartum involution (asymmetric horns, uterine wall striations, palpable caruncules, etc) were discarded. After examination, 100 apparently normal reproductive tracts were selected for the study and transported to the laboratory of Reproduction \& Obstetrics at the Veterinary Faculty of Lugo.

Data on reproductive performance of the cows or reasons for culling were unknown, and considered irrelevant for the study, as the objective was to evaluate agreement between diagnosis methods irrespective of potential causes or consequences of SCE.

\section{Collection of samples}

Ovarian structures (corpora lutea, follicles and dominant follicles) present in the ovaries of each reproductive tract were recorded. Samples for microbiological exam were taken from the cranial portion of each uterine horn, samples for histological evaluation were taken from the medium third of each horn and samples for endometrial cytology were taken from the caudal third of each uterine horn. Different uterine regions were used for the different samples to avoid potential artifacts induced by the sampling procedures.

\section{Microbiological samples}

On the cranial part of each horn, the external surface of the uterine wall was sterilized using a flame heated spatula in order to prevent external contamination of the endometrium. On the sterilized area, the uterine wall was incised using a sterile surgical scalpel and a sterile swab was introduced and rolled against the endometrial surface. Swabs were placed in plastic tubes without transport medium (Eurotubo, Deltalab SL, Barcelona, Spain) and immediately delivered at the laboratory of Infectious Diseases of the Veterinary Faculty of Lugo. Bacteriological samples were cultured for aerobic and anaerobic bacteria by routine methods of bacteriological testing (Carter and Cole, 1990; Koneman, 2006). Bacteria were identified based on colony characteristics, Gram staining, hemolytic ability, and biochemical profile. For virus identification, swabs were eluted in $1 \mathrm{ml}$ of PBS. DNA/RNA was extracted from eluates by using commercial extraction kits and following the manufacturer's instructions: Nucleospin RNA (Macherey-Nagel, Germany) and Nucleospin tissue (Macherey-Nagel, Germany). DNA extracts were tested by real time PCR for detecting BoHV-4, BoHV-1 by using the following commercial PCR kits: TaqVet Bovine Herpesvirus 4 (Life technologies, USA), TaqVet IBR (Life technologies, USA); similarly, RNA extracts were used to test the presence of RNA of BVDV by using TaqVet BVDV Screening (Life technologies, USA).

\section{Samples for histological evaluation}

From the middle of each uterine horn, a slice was cut with scissors and from that slice, a piece of uterine wall of approximately $2 \times 2 \mathrm{~cm}$ was fixed in $10 \%$ formaldehyde buffered solution and delivered at the laboratory of Histopathology of the Veterinary Faculty. Histological samples were processed by routine methods (Lee and Luna, 1968). Briefly, formalin-fixed tissues were dehydrated through a graded series of ethanol solutions, paraffin-embedded, sectioned at 5-6 $\mu \mathrm{m}$ thickness, and stained with hematoxylin-eosin, Mallory's staining and periodic acid-Schiff technique. All samples were evaluated by duplicate by the same skilled pathologist, at $400 \mathrm{X}$ microscopic magnification, and scored following the criteria specified in Table 1.

Intrauterine fluid, if any, was identified at the time of removing slices of uterine horns. The characteristics of any intrauterine fluid were classified as follows: $0=$ no fluid; $1=$ mucous (transparent and crystalline mucus); 2= abnormal (mucopurulent, purulent or bloody mucus). 
Table 1. Criteria used to score samples for histological evaluation.

\begin{tabular}{|c|c|}
\hline Histological parameters & Values \\
\hline $\begin{array}{l}\text { Endometrial epithelium } \\
\text { status }\end{array}$ & $\begin{array}{l}0=\text { normal epithelium } \\
1=\text { epithelium with normal structure but with more than } 5 \text { inflammatory cells } \\
\text { along the epithelium } \\
2=\text { presence of a pyogenic membrane on the epithelium }\end{array}$ \\
\hline $\begin{array}{l}\text { Degree of endometrial } \\
\text { inflammation }\end{array}$ & $\begin{array}{l}0=\text { no inflammatory infiltrate }(<3 \text { PMN per } 400 \mathrm{X} \text { microscopic field }) \\
1=\text { low: } 3-6 \text { PMN per } 400 \mathrm{X} \text { field } \\
2=\text { moderate: } 7-10 \text { PMN per } 400 \mathrm{X} \text { field } \\
3=\text { severe: }>10 \text { PMN per } 400 \mathrm{X} \text { field }\end{array}$ \\
\hline $\begin{array}{l}\text { Infiltrate distribution in the } \\
\text { endometrium }\end{array}$ & $\begin{array}{l}0=\text { no inflammatory infiltrate } \\
1=\text { periglandular: inflammatory infiltrate in the stratum spongiosum } \\
2=\text { diffuse: inflammatory infiltrate in the stratum compactum } \\
3=\text { periglandular and diffuse: inflammatory infiltrate in the stratum spongiosum } \\
\quad \text { and compactum }\end{array}$ \\
\hline $\begin{array}{l}\text { Endometrial gland } \\
\text { morphology }\end{array}$ & $\begin{array}{l}0=\text { normal glands } \\
1=\text { dilated glands: }>25 \% \text { of the endometrial glands had a lumen higher than twice } \\
\text { the height of the glandular epithelium. } \\
2=\text { cystic glands: }>25 \% \text { of the endometrial glands had dilated lumen and } \\
\text { hypoplastic epithelium. } \\
3=\text { dilated and cystic glands: }>25 \% \text { of the endometrial glands were dilated or } \\
\text { cystic }\end{array}$ \\
\hline $\begin{array}{l}\text { Presence of endometrial } \\
\text { fibrosis }\end{array}$ & $\begin{array}{l}0=\text { no fibrosis } \\
1=\text { presence of } 1 \text { or } 2 \text { concentric layers of fibroblasts } \\
2=\text { presence of } 3-5 \text { layers of fibroblasts } \\
3=\text { presence of }>6 \text { layers of fibroblasts }\end{array}$ \\
\hline Fibrosis distribution & $\begin{array}{l}0=\text { no fibrosis } \\
1=\text { periglandular fibrosis } \\
2=\text { diffuse fibrosis } \\
3=\text { periglandular and diffuse fibrosis }\end{array}$ \\
\hline
\end{tabular}

Samples for endometrial cytology

A cytobrush was introduced into the caudal end of uterine horns, rolled against the endometrial surface, and rotated on a microscopic slide. Smears were stained with Diff Quick ${ }^{\circledR}$ staining (DMV, Barcelona, Spain), and evaluated under a microscope at $400 \mathrm{X}$ magnification, where 250 cells were counted to determine the percentages of PMN. Cut-off value for positive cytology was established at $\geq 5 \%$ PMN. All samples were evaluated by duplicate and by the same person.

\section{Statistical analysis}

Statistical analysis was performed using the SPSS 22.0 software package (IBM SPSS, Armonk, NY, USA). First, bacteriology results (positive or negative cultures), histological findings (epithelium status, presence of infiltrate and infiltrate distribution, gland morphology, presence of fibrosis and fibrosis distribution), presence and type of intrauterine fluid, and endometrial cytology (positive or negative) were compared by means of Receiver/Response Operating Characteristics (ROC) curve analysis using endometrial cytology as the gold standard (cut-off value $\geq 5 \% \mathrm{PMN}$ ).
Parameters for which ROC curves indicated significant agreement $(\mathrm{P}<0.05)$ with cytology were used to classify samples as positive or negative, at cut-off values of the highest sensitivity and specificity, and recompared with endometrial cytology by means of Cohen's Kappa analysis. Second, results from paired uterine horns were compared using Cohen's Kappa (cytology and biopsy) and/or Chi-square methods. Finally, the relationship between cytological, histological and bacteriological findings was evaluated by Chi-squared method.

\section{Results}

From the 100 genital tracts used in this study, 73 were in luteal phase and 27 in follicular phase. The phase of the estrus cycle had no significant influence on endometrial cytology, microbiological results, or presence of intrauterine content. The presence of an endometrial inflammatory infiltrate diagnosed by histology (biopsy positive samples, specified below), was the only parameter influenced by the phase of the estrus cycle $(\mathrm{P}<0.001)$, with 16.4 and $39.9 \%$ positive biopsies for the luteal and follicular phases, respectively.

Presence of an inflammatory infiltrate and its 
distribution within the endometrium were the only histological parameters that significantly agreed with the results of endometrial cytology. Status of endometrial epithelium, morphology of endometrial glands or existence of fibrosis, as well as presence of intrauterine fluid or positive culture, had no relationship with cytological results. ROC curves analysis for the parameters evaluated are shown in Table 2.

Uteri with an inflammatory infiltrate diagnosed by histology, regardless of degree and distribution of inflammation, were re-classified as biopsy positive samples (cut-off values indicated by maximum values of sensitivity and specificity by ROC curves analysis) and re-compared with cytology results by using the Cohen's Kappa method. Moderate degree of agreement (sensitivity: 69\%; specificity: $87 \%$; kappa $=0.55 \pm 0.07$ ) was observed between uterine cytology and biopsy in relation to the presence of endometrial inflammation (Fig. 1) and low degree of agreement (kappa.=.0.30...0.06) in relation to infiltrate distribution (Fig. 2).

Table 2. ROC curves analysis: endometrial histology, bacteriology and intrauterine content were compared with endometrial cytology as gold standard (cut-off value $\geq 5 \%$ PMN per 400X microscopic field; $n=200$ ).

\begin{tabular}{llll}
\hline Parameters compared & AUC & Error & Significance \\
\hline Histological findings & & & .914 \\
Epithelium status & .507 & .060 & .229 \\
Glandular morphology & .426 & .055 & .000 \\
Inflammatory infiltrate & .780 & .059 & .002 \\
Infiltrate distribution & .694 & .056 & .351 \\
Endometrial Fibrosis & .557 & .056 & .695 \\
Fibrosis distribution & .476 & .056 & .931 \\
Bacteriology & .495 & .061 & .131 \\
Intrauterine content & .593 & .064 & \\
\hline
\end{tabular}

AUC: Area under the curve

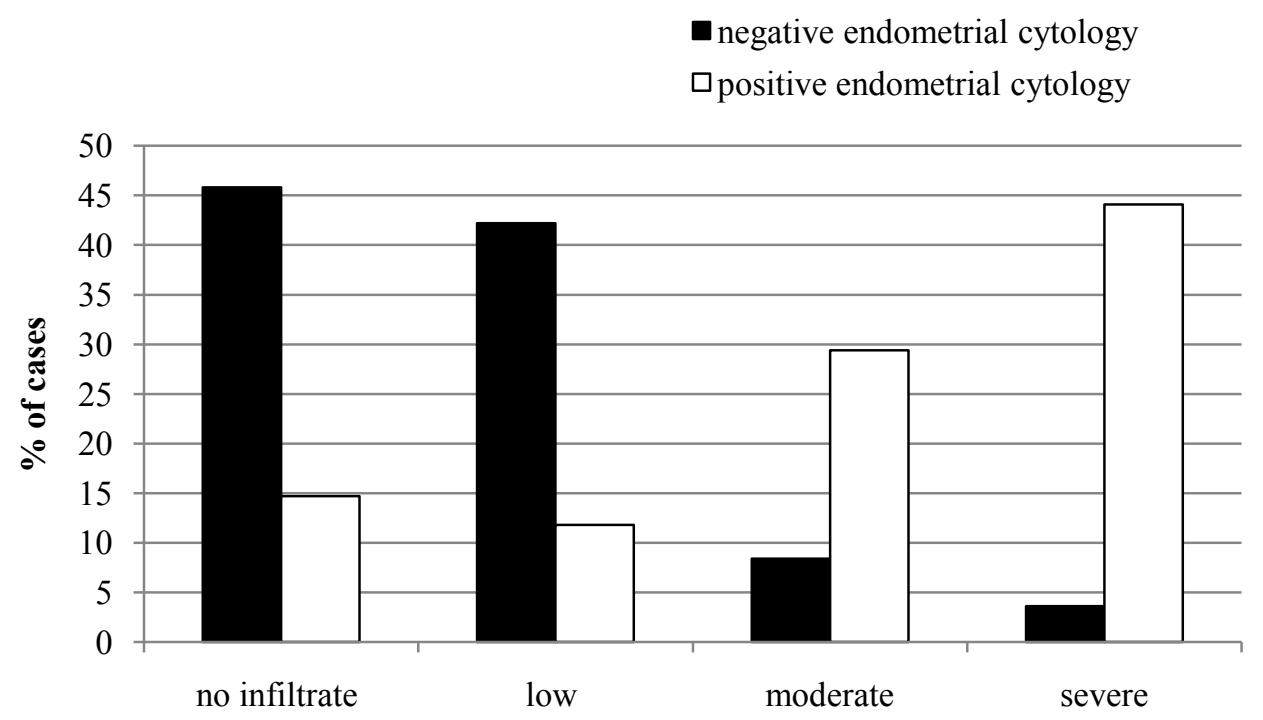

Degree of endometrial inflammation as seen by histology

Figure 1. Comparison between endometrial cytology and histology depending on the degree of inflammation.

When cytology results were compared between paired uterine horns (Fig. 3) moderately high agreement was observed (kappa $=0.65 \pm 0.10)$. In $92 \%$ of cases, negative cytology of the left horn indicated negative cytology of both uterine horns, whereas $20 \%$ of cytology negative right horns corresponded to cytology positive left horns. When comparing biopsy between paired uterine horns, higher level of agreement was observed (kappa $=0.74 \pm 0.08$ ), and again, the left horn was more representative of both horns than the right one (Fig. 4).

Concerning histological findings in paired uterine horns, degree of inflammation and infiltrate distribution were mostly coincident in both uterine horns $(\mathrm{P}<0.01)$.

When none or low degree of endometrial inflammation was observed in the left horn, in $83 \%$ of cases, the same results were obtained for the right horn. Severe endometrial inflammation was always observed in the two horns. The highest discrepancies between horns were observed in cases of moderate endometrial inflammation, of which 58\% were diagnosed in the two horns (Fig. 5). In more than $85 \%$ of cases, the inflammatory infiltrate was similarly distributed in the endometrium of both uterine horns (Fig. 6).

There was no relationship between cytology or biopsy and bacteriology results. Positive cultures were obtained from $11.8 \%$ of horns with positive cytology 
and biopsy, and from $12.3 \%$ of horns with negative cytology and biopsy. Interestingly, different microorganisms were isolated from horns with negative or positive cytology (Fig. 7). Paired horns were both negative for bacteriology in $83 \%$ of cases and positive in $7 \%$ of them. When positive, the same bacteria were isolated from the two horns. In $10 \%$ of cases, the right horn was negative and the left horn positive for bacteriology, but all the negative left horns corresponded to negative right horns. All the samples were negative for IBR, BVDV or BoHV4.

The presence and characteristics of any intrauterine content did not significantly differ between samples with positive or negative cytology. However, a significant relationship ( $\mathrm{P}=0.036)$ was found between intrauterine content and biopsy results. Absence of intrauterine content was found in $67.1 \%$ of horns with negative biopsy and in $55.8 \%$ of horns with positive biopsy. Clean transparent mucus was found in $21.1 \%$ of biopsy negative horns and in $16.3 \%$ of biopsy positive horns and abnormal uterine content (mucopurulent, purulent or bloody mucus) was found in $11.8 \%$ of biopsy negative horns and in $27.9 \%$ of biopsy positive horns.

negative endometrial cytology

$\square$ positive endometrial cytology

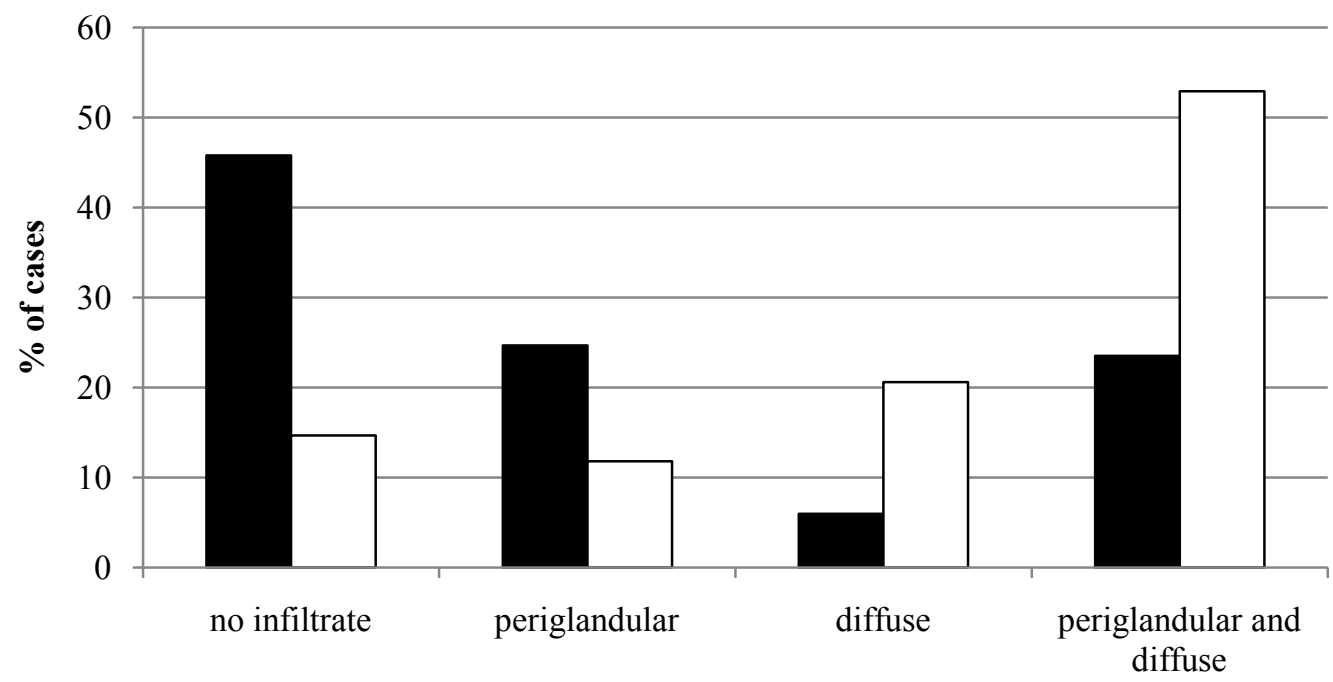

Infiltrate distribution as seen by histology

Figure 2. Comparison between endometrial cytology and histology depending on the infiltrate distribution.

negative cytology in right horn

$\square$ positive cytology in right horn

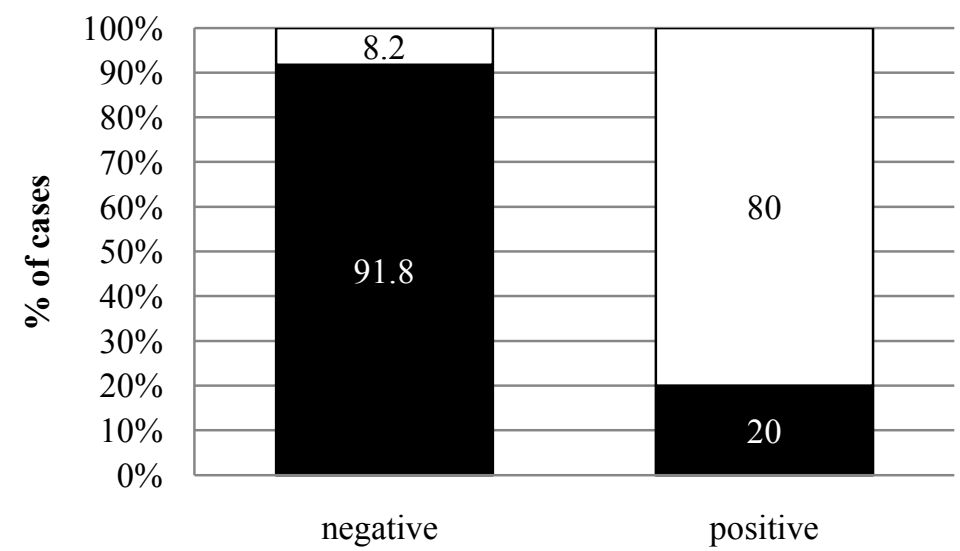

Cytology of the left horn

Figure 3. Comparison of cytology results between paired uterine horns. 
$\square$ positive histology in right horn

negative histology in right horn

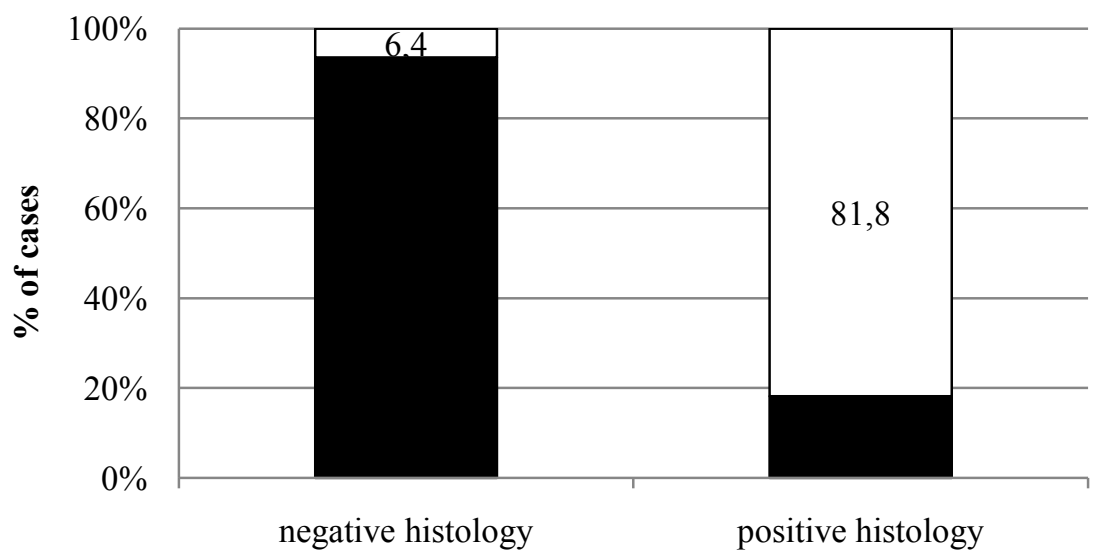

Histology of the left horn

Figure 4. Comparison of biopsy results between paired uterine horns.

$\square$ no infiltrate in right horn

$\square$ moderate inflammation in right horn $\square$ low inflammation in right horn

- severe inflammation in right horn

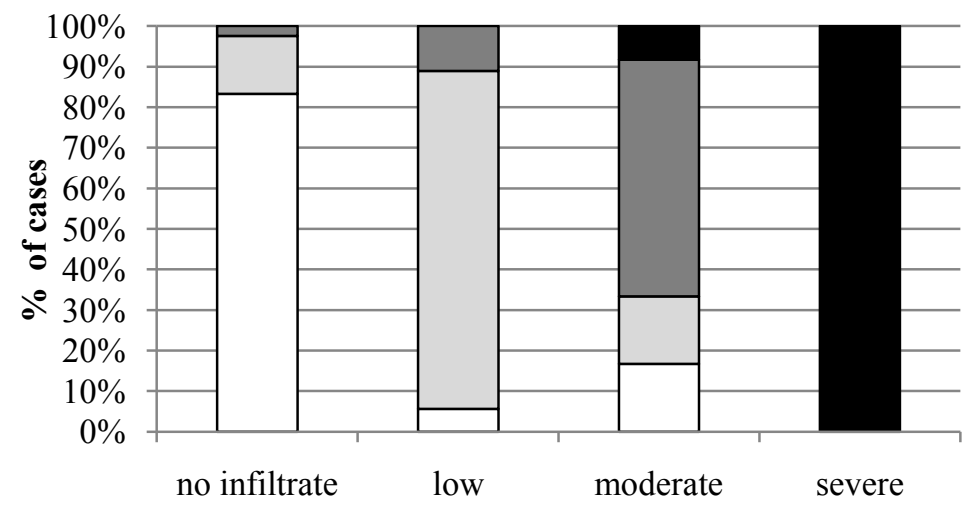

Degree of endomterial inflamation of the left horn as seen by histology

Figure 5. Comparison between paired uterine horns for degree of endometrial inflammation as seen by histology.

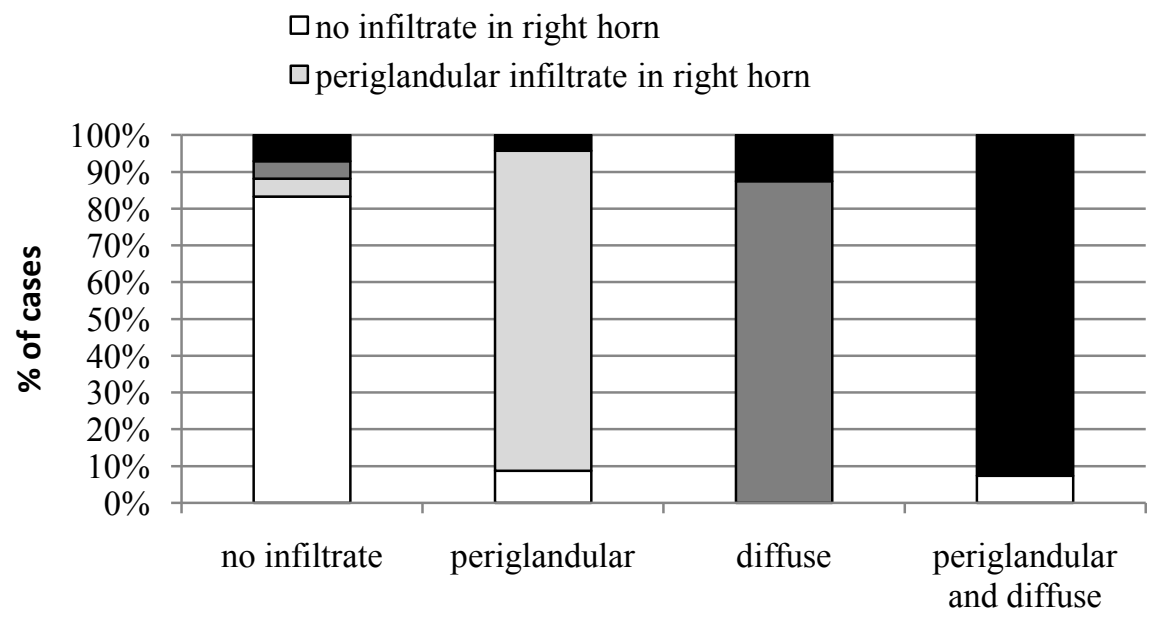

Infiltrate distribution in the left horn as seen by histology

Figure 6. Comparison between paired uterine horns for distribution of endometrial infiltrate as seen by histology. 


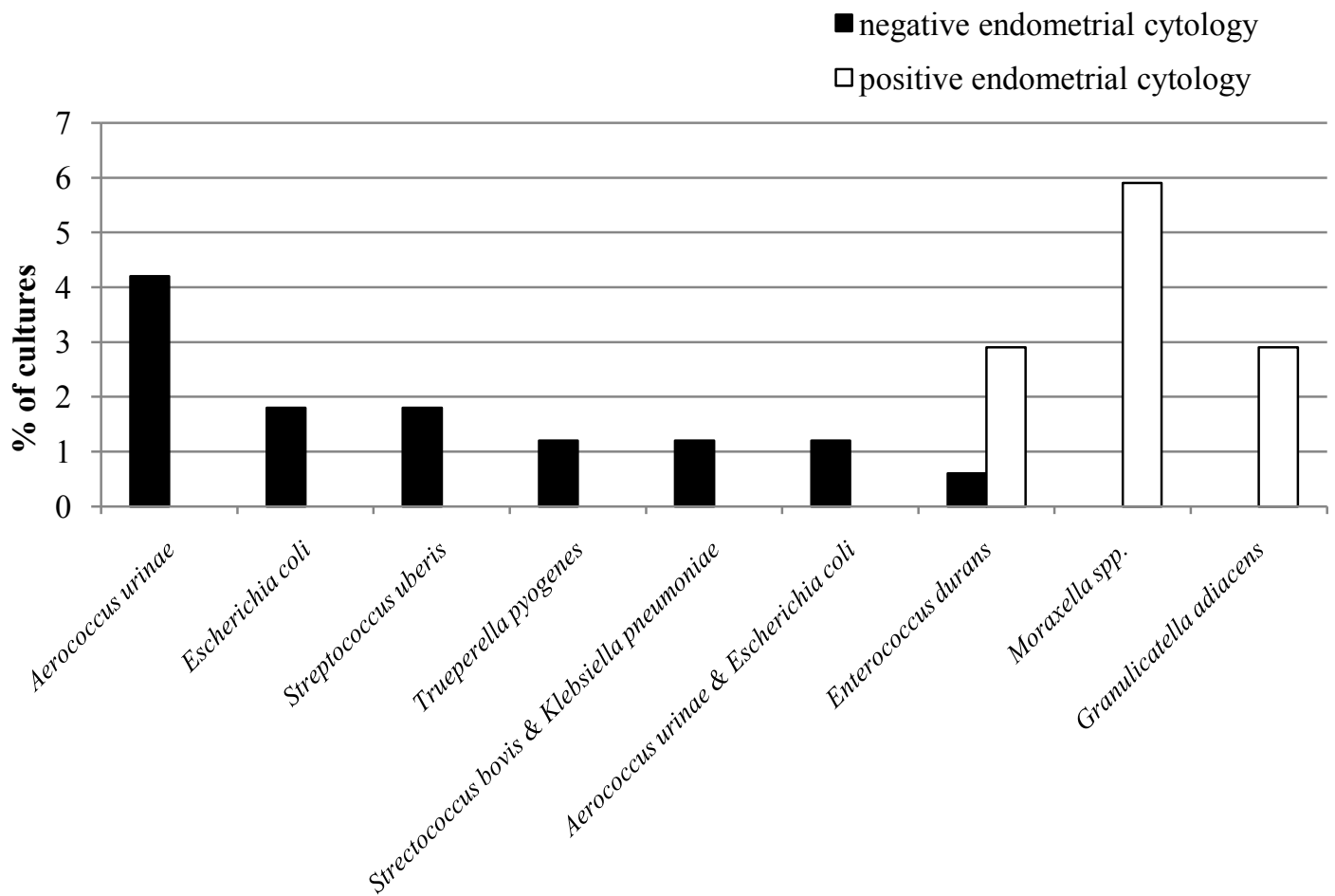

Microorganisms isolated from positive culures

Figure 7. Microorganisms isolated from positive cultures depending on cytology.

\section{Discussion}

\section{Agreement between diagnosis methods}

From the histological parameters evaluated in uterine biopsies, the presence of an inflammatory infiltrate and its endometrial distribution were significantly correlated with the cytology results (Table 1). Such correlation seems rather obvious since the inflammatory cells collected from the uterine surface by cytobrushing come from the endometrium (Sheldon et al., 2009; Shao et al., 2012) and, although a negative cytology cannot exclude the existence of endometrial inflammation, a high degree of agreement between cytology and biopsy should be expected. However, the present results showed that the degree of agreement between the two methods was moderate for presence of inflammation (kappa $=0.55)$ and low for infiltrate distribution (kappa $=0.30)$. Meira et al. $(2012)$ and Madoz et al. (2014) also found moderate (kappa $=0.39)$ and low agreement (kappa $=0.151)$, respectively, between uterine cytology and biopsy for diagnosing endometrial inflammation. The discordance between diagnostic methods can be explained, at least in part, by the finding that cytology failed to identify most of the samples with low degree of inflammation (Fig. 1). Moreover, because cytology only assesses the superficial layer of the endometrium, a negative cytology can be obtained from uterine samples with inflammatory infiltrate in deeper layers. In fact, it was observed that when the inflammatory infiltrate had a periglandular distribution in the spongiosum stratum, in about $66 \%$ of the cases the cytology was negative (Fig.
2). On the other hand, the cut-off point of \% PMN established for positive cytology may have influenced the agreement between the two techniques, since it was found that about $15 \%$ of healthy uteri diagnosed by histology were classified with positive cytology. As previously reported by Madoz et al. (2013), in the present study, cytology outputs were not influenced by the phase of the estrus cycle at the time of diagnosis. However, by using biopsy, a higher degree of inflammatory infiltration could be detected during the follicular phase of the cycle.

Other histological characteristics evaluated in this study, such as for example cystic dilatation of endometrial glands or endometrial fibrosis, showed no correlation with cytology results. This was to be expected as the majority of the inflammatory lesions observed here did not involve the endometrial glands. In the study of Meira et al. (2012) uterine biopsy showed a better diagnostic efficiency for SCE as compared with cytology, when the glandular inflammation status was excluded from histological evaluation. This suggests that cronic endometritis, typically involving cystic glands and periglandular fibrosis (Ahmadi et al., 2005), may not be detected by cytology.

The presence of intrauterine fluid, either clean or abnormal, had no relationship with cytology outputs. In previous studies, the presence of uterine fluid detected by ultrasound was associated to negative effects on fertility (Kasimanickam et al., 2004; Barlund et al., 2008), however, it had low sensitivity and agreement with endometrial cytology was low, with kappa values lower than 0.35 (Kasimanickam et al., 2004; Barlund et al., 2008; Meira et al., 2012). 
Ultrasonographic assessment of uterine fluid may lead to some diagnostic errors as some fluid into the uterus may be normal during the estrus period or when uterine involution is incomplete, which might partially account for the low agreement with cytology. In the present study we could ascertain the lack of agreement between presence of abnormal fluid into the uterus and cytology. Kasimanickam et al. (2004) suggested that cytology and ultrasound are measuring different causative factors, cytology measuring the cellular response and ultrasound the clearance mechanism of the uterus. However, in this study, a significant relationship was found between presence of intrauterine content and positive biopsy samples, which suggests that cytology was not sensitive enough.

In summary, the present results indicated that cytology failed to detect cases of subclinical endometritis with low degree of inflammation or with a predominantly periglandular distribution of infiltrate. The histopathological examination of biopsy samples gives much more detailed information about the degree of inflammation and the lesions that may exist (Meira et $a l ., 2012$ ), and probably it should be considered the gold standard for the diagnosis of SCE. However, uterine cytology showed a moderately high degree of agreement and is quicker and easier to perform and probably safer, than uterine biopsy. Therefore, cytology might be an alternative diagnostic tool for the SCE diagnosis.

\section{Comparison between uterine horns}

Samples for endometrial cytology or biopsy are usually collected from one uterine horn assuming the sample is representative of both horns. The present results showed that this assumption is generally true, but not always. When the cytology or the biopsy was taken from the left horn, a negative result indicated that, in more than $90 \%$ of the cases, the right horn was also negative. However, when the sample was obtained from the right horn, in about $20 \%$ of the negative cases the left horn was positive (Fig. 3). Certain disagreement between cytology or biopsy from both uterine horns was to be expected, as endometrial inflammation may be local or diffuse, and it may not necessarily affect the whole endometrium. However, the reason why a sample from the left horn seems to be more representative than one from the right one is not known. To our knowledge there are no other studies comparing cytology or biopsy between uterine horns. This may have been an occasional finding, but if it were confirmed in further studies, it should be taken into account for the diagnosis of SCE.

\section{Uterine microbiology}

Bacterial isolation had no significant correlation with cytology or biopsy results. Only a few studies investigated bacterial populations present in the uterus of cows with SCE (Lazzari et al., 2011; McDougall et al., 2011; Madoz et al., 2014) and in general, low level of agreement was observed between the presence of intrauterine pathogens and cytological endometritis. The negative effects of SCE on fertility are believed to be more the consequence of uterine inflammation rather than of uterine bacterial infection (Green et al., 2009; Burke et al., 2010; McDougall et al., 2011).

Different bacterial species were isolated from uteri with negative or positive cytology. Whereas from cytology negative horns some recognized pathogens were isolated, such as E. coli and T. pyogenes (Sheldon et al., 2002, 2010; Amos et al., 2014) or S. uberis, the major causative agent for bovine mastitis (Schunkken et al., 2013), from cytology positive horns nonspecific or low pathogenic bacteria were found. These findings agree with previous studies showing that large microbial diversity can be identified in the uterus of dairy cows, irrespective of their uterine health status (Santos et al., 2011). The natural defense mechanisms eliminate many of the microorganisms but the efficiency of elimination depends on the bacterial load and pathogenicity as well as on the immune status of the cow (Sheldon et al., 2002). Concerning bacteriology results from paired uterine horns, again the left horn was more representative of the infectious status of the uterus than the right one. As previously discussed for cytology and biopsy, there was not an obvious explanation for this finding, which should be further investigated.

In conclusion, although endometrial biopsy may be the most accurate method for the diagnosis of SCE, cytology and biopsy results agreed moderately well $($ kappa $=0.55)$, which confirmed the usefulness of cytology. Positive endometrial cytology and/or biopsy did not indicate the existence of bacterial infection. In most cases, but not in the $100 \%$, cytology, biopsy and bacteriology results were the same for both uterine horns. Whether the left horn is more representative of the uterine health status than the right one still has to be confirmed.

\section{Acknowledgments}

The study was supported by Xunta de Galicia (Proyecto RUMIGAL: Rede de estudio multidisciplinar dos ruminantes de Galicia).

\section{References}

Ahmadi MR, Khodakaram Tafti A, Nazifi S, Ghaisari HR. 2005. The comparative evaluation of uterine and cervical mucosa cytology with endometrial histopathology in cows. Comp Clin Pathol, 14:90-94.

Amos MR, Healey GD, Goldstone RJ, Mahan SM, Duvel A, Schuberth HJ, Sandra O, Zieger P, DieuzyLabaye I, Smith DG, Sheldon IM. 2014. Differential endometrial cell sensitivity to a cholesterol-dependent cytolysin links Trueperella pyogenes to uterine disease in cattle. Biol Reprod, 90:54. doi: 10.1095/biolreprod.113.115972.

Barlund CS, Carruthers TD, Waldner CL, Palmer CW. 2008. A comparison of diagnostic techniques for postpartum endometritis in dairy cattle. Theriogenology, 69:714-723. 
Barrio M, Vigo M, Quintela LA, Becerra JJ, Herradón PG, Martínez-Bello D, Fernández-Sánchez F, Prieto A, Cainzos J, Peña AI. 2015. Influence of subclinical endometritis on the reproductive performance of dairy cows. Span J Agric Res, 13(4):e05SC02.

Bartlett PC, Kirk JH, Wilke MA, Kaneene JB, Mather EC. 1986. Metritis complex in Michigan Holstein-Friesian Cattle: Incidence, descriptive epidemiology and estimated economic impact. Prev Vet Med, 4:235-248.

Burke CR, Meier S, McDougall S, Compton C, Mitchell M, Roche JR. 2010. Relationships between endometritis and metabolic state during the transition period in pasture-grazed dairy cows. $J$ Dairy Sci, 93:5363-5373.

Carter GR, Cole JR. 1990. Diagnostic Procedure in Veterinary Bacteriology and Mycology. 5th ed. San Diego, CA: Academic Press. 620 pp.

Földi J, Kulcsara M, Pecsi A, Huygheb B, de Sa C, Lohuis JACM, Cox P, Huszenicza G. 2006. Bacterial complications of postpartum uterine involution in cattle. Anim Reprod Sci, 96:265-281.

Gilbert RO, Shin ST, Guard CL, Erb HN, Frajblat M. 2005. Prevalence of endometritis and its effects on reproductive performance of dairy cows. Theriogenology, 64:1879-1888.

Green MP, Ledgard AM, Berg MC, Peterson AJ, Back PJ. 2009. Prevalence and identification of systemic markers of sub-clinical endometritis in postpartum dairy cows. Proc NZ Soc Anim Prod, 69:37-42.

Guard CL. 1994. Costs of clinical disease in dairy cows. In: Proceedings of the Annual Cornell Conference on Veterinary Medicine, 1994, Ithaca, NY Ithaca, NY: Cornell Univ.

Kasimanickam R, Duffield TF, Foster RA, Gartley CJ, Leslie KE, Walton JS, Johnson WH. 2004. Endometrial cytology and ultrasonography for the detection of subclinical endometritis in postpartum dairy cows. Theriogenology, 62:9-23.

Kasimanickam R, Duffield TF, Foster RA, Gartley CJ, Leslie KE, Walton JS, Johnson WH. 2005. The effect of a single administration of cephapirin or cloprostenol on the reproductive performance of dairy cows with subclinical endometritis. Theriogenology, 63:818-830.

Koneman E, Winn W, Allen S, Janda W, Koneman E, Procop G, Schreckenberger P, Woods G. 2006. Koneman's Color Atlas and Textbook of Diagnostic Microbiology. Baltimore, MD: Lippincott Williams \& Wilkins. 1565 pp.

Küçükaslan I, Kaya D, Emre B, Bollwein $\mathbf{H}$, Özyurtlu N, Mülazımoglu SB, Aslan S. 2014. Evaluation of endometrial echotexture and cervical cytology in cows during and after treatment of endometritis. Tierärztl Prax Ausg $G$ Grosstiere Nutztiere, 42:343-350.

Lazzari G, Duchi R, Colleoni S, Baldazzi L, Benedetti V, Galli A, Luini M, Ferrari M, Galli C 2011. Le patologie uterine cliniche e subcliniche come causa di infertilità nelle bovine da latte: studio epidemiologico in due allevamenti della regione
Lombardia. Large Anim Rev, 17:43-47.

Lee G, Luna HT. 1968. Manual of Histological Staining Methods of the Armed Forces Institute of Pathology. New York, NY: McGraw-Hill. 258 pp.

López-Gatius F. 2003. Is fertility declining in dairy cattle? A retrospective study in northeastern Spain. Theriogenology, 60:89-99.

Lucy MC. 2001. Reproductive loss in high-producing dairy cattle: where will it end? J Dairy Sci, 84:12771293.

Madoz LV, Giuliodori MJ, Jaureguiberry M, Plontzke J, Drillich M, de la Sota RL. 2013. The relationship between endometrial cytology during estrus cycle and cutoff points for the diagnosis of subclinical endometritis in grazing dairy cows. $J$ Dairy Sci, 96:4333-4337.

Madoz LV, Giuliodori MJ, Migliorisi AL, Jaureguiberry M, de la Sota RL. 2014. Endometrial cytology, biopsy, and bacteriology for the diagnosis of subclinical endometritis in grazing dairy cows. J Dairy Sci, 97:195-201.

McDougall S, Husseina H, Aberdein D, Buckle K, Roche J, Burke C, Mitchell M, Meier S. 2011. Relationships between cytology, bacteriology and vaginal discharge scores and reproductive performance in dairy cattle. Theriogenology, 76:229-240.

Meira Jr. EBS, Henriques LCS, Sá LRM, Gregory L. 2012. Comparison of ultrasonography and histopathology for the diagnosis of endometritis in Holstein-Friesian cows. J Dairy Sci, 95:6969-6973.

Melcher Y, Prunner I, Drillich M. 2014. Degree of variation and reproducibility of different methods for the diagnosis of subclinical endometritis. Theriogenology, 82:57-63.

Oral H, Sozmen M, Serin G, Kaya S. 2009. Comparison of the cytobrush technique, vaginoscopy and transrectal ultrasonography methods for the diagnosis of postpartum endometritis in cows. $J$ Anim Vet Adv, 8:1252-1255.

Plazier JCB, King GJ, Dekkers JCM, Lissemore K. 1997. Estimation of economic values of indices for reproductive performance in dairy herds using computer simulation. J Dairy Sci, 80:2775-2783.

Prieto M, Barrio M, Quintela LA, Perez-Martin CC, Becerra JJ, Vigo M, Diaz C, Cainzos J, Prieto A, Fernandez FI, Martinez D, Herradon PG. 2012. Validation of simple method for the interpretation of uterine cytology in cows. Vet Med, 57:360-363.

Royal M, Mann GE, Flint AP. 2000. Strategies for reversing the trend towards subfertility in dairy cattle. Vet $J, 160: 53-60$.

Santos TMA, Gilbert R, Bicalho RC. 2011. Metagenomic analysis of the uterine bacterial microbiota in healthy and metritic postpartum dairy cows. J Dairy Sci, 94:291-302.

Schukken YH, Zurakowski MJ, Rauch BJ. Gross B, Tikofsky LL, Welcome FL. 2013. Noninferiority trial comparing a first-generation cephalosporin with a thirdgeneration cephalosporin in the treatment of nonsevere clinical mastitis in dairy cows. J Dairy $S c i, 81: 6763$ 6774.

Shao CY, Wang H, Meng X, Zhu JQ, Wu YQ, Li JJ. 
2012. Characterization of the innate immune response in goats after intrauterine infusion of E. coli using histopathological, cytologic and molecular analyses. Theriogenology, 78:593-604.

Sheldon IM, Noakes DE, Rycroft AN, Pfeiffer DU, Dobson H. 2002. Influence of uterine bacterial contamination after parturition on ovarian dominant follicle selection and follicle growth and function in cattle. Reproduction, 123:837-845.

Sheldon IM, Lewis GS, LeBlanc S, Gilbert RO. 2006. Defining postpartum uterine disease in cattle. Theriogenology, 65:1516-1530.

Sheldon IM, Cronin J, Goetze L, Donofrio G,
Schuberth HJ. 2009. Defining postpartum uterine disease and the mechanisms of infection and immunity in the female reproductive tract in cattle. Biol Reprod, 81:1025-1032.

Sheldon IM, Rycroft AN, Dogan B, Craven M, Bromfield JJ, Chandler A, Roberts MH, Price SB, Gilbert RO, Simpson KW. 2010. Specific strains of Escherichia coli are pathogenic for the endometrium of cattle and cause pelvic inflammatory disease in cattle and mice. Plos One, 5:e9192.

Walsh SW, Williams EJ, Evans ACO. 2011. A review of the causes of poor fertility in high milk producing dairy cows. Anim Reprod Sci, 123:127-138. 